\title{
Response of atmospheric carbon dioxide to the secular variation of weakening geomagnetic field in whole atmosphere simulations
}

\author{
Xu Zhou ${ }^{1,2,3,4}$, XinAn Yue ${ }^{1,2,3,4}{ }^{*}$, Han-Li Liu' ${ }^{5}$, Yong Wei ${ }^{1,2,3,4}$, and YongXin Pan ${ }^{1,2,4}$ \\ ${ }^{1}$ Key Laboratory of Earth and Planetary Physics, Institute of Geology and Geophysics, Chinese Academy of Sciences, Beijing 100029, China; \\ Innovation Academy for Earth Science, Chinese Academy of Sciences, Beijing 100029, China; \\ ${ }^{3}$ Beijing National Observatory of Space Environment, Institute of Geology and Geophysics, Chinese Academy of Sciences, Beijing 100029, China; \\ ${ }^{4}$ College of Earth and Planetary Sciences, University of Chinese Academy of Sciences, Beijing 100049, China; \\ ${ }^{5}$ High Altitude Observatory, National Center for Atmospheric Research, Boulder, CO, USA \\ Key Points: \\ - WACCM-X simulations reveal that geomagnetic field weakening enhances Joule heating and affects atmospheric $\mathrm{CO}_{2}$ distribution. \\ - Geomagnetic secular variation redistributes $\mathrm{CO}_{2}$ above $\sim 90 \mathrm{~km}$ altitude, altering the energy budget at $\sim 100-110 \mathrm{~km}$. \\ - $\mathrm{CO}_{2}$ volume mixing ratios increase (decrease) at high latitudes (mid and low latitudes) in response to geomagnetic weakening.
}

Citation: Zhou, X., Yue, X. A., Liu, H.-L., Wei, Y. and Pan, Y. X. (2021). Response of atmospheric carbon dioxide to the secular variation of weakening geomagnetic field in whole atmosphere simulations. Earth Planet. Phys., 5(4), 327-336. http://doi.org/10.26464/epp2021040

\begin{abstract}
Responses of atmospheric carbon dioxide $\left(\mathrm{CO}_{2}\right)$ density to geomagnetic secular variation are investigated using the Whole Atmosphere Community Climate Model-eXtended (WACCM-X). Our ensemble simulations show that $\mathrm{CO}_{2}$ volume mixing ratios (VMRs) increase at high latitudes and decrease at mid and low latitudes by several ppmv in response to a $50 \%$ weakening of the geomagnetic field. Statistically significant changes in $\mathrm{CO}_{2}$ are mainly found above $\sim 90 \mathrm{~km}$ altitude and primarily redetermine the energy budget at 100-110 km. Our analysis of transformed Eulerian mean (TEM) circulation found that $\mathrm{CO}_{2}$ change is caused by enhanced upwelling at high latitudes and downwelling at mid and low latitudes as a result of increased Joule heating. We further analyzed the atmospheric $\mathrm{CO}_{2}$ response to realistic geomagnetic weakening between 1978 and 2013, and found increasing (decreasing) $\mathrm{CO}_{2} \mathrm{VMRs}$ at high latitudes (mid and low latitudes) accordingly. For the first time, our simulation results demonstrate that the impact of geomagnetic variation on atmospheric $\mathrm{CO}_{2}$ distribution is noticeable on a time scale of decades.
\end{abstract}

Keywords: atmospheric carbon dioxide; geomagnetic fields; whole atmosphere simulation; upper atmosphere

\section{Introduction}

Previous studies indicate that variation in the geomagnetic field has the potential to influence climate changes in the upper atmosphere by affecting the motion of ions and electrons, ion-neutral coupling, and thus the energy budget, despite that changes in the geomagnetic field do not act directly on the neutral atmosphere. The underlying physical mechanism has been investigated through idealized modeling (Cnossen et al., 2011, 2012; Cnossen and Richmond, 2012; Zossi et al., 2018). One widely accepted view is that geomagnetic field changes lead to different ionospheric conductivities and electric fields, which results in different Joule heating rates that influence the temperature, dynamics, and composition of the neutral upper atmosphere.

However, the effect of geomagnetic field variation on the middle and lower atmosphere down to the surface remains controversial.

Correspondence to: X. A. Yue, yuexinan@mail.iggcas.ac.cn

Received 27 APR 2021; Accepted 05 JUL 2021.

Accepted article online 08 JUL 2021.

(C)2021 by Earth and Planetary Physics.
Wollin et al. (1971) first proposed a linkage between the geomagnetic field and surface climate based on the study of deep-sea sediment cores. Researchers further found a negative correlation between the strength of geomagnetic fields and global mean surface temperature, inferred from the measured rise and fall of global sea level as well as the advance and retreat of Alpine glaciers (e.g., Gallet et al., 2005; De Santis et al., 2012). Kitaba et al. (2013) also suggested that tropospheric cooling could decrease the geomagnetic field. Although several lines of observational evidence have suggested a correlation between the geomagnetic field and climate, the mechanism is unclear. One hypothesis, the so-called "umbrella effect", postulates that a strong geomagnetic field could reduce cosmic rays flux, affecting cloud formation (e.g., Kitaba et al., 2017; Svensmark et al., 2017). Others have proposed that geomagnetic field modulation in the upper atmosphere would have downward influences on chemical and dynamic processes in the lower atmosphere, including wave propagation (e.g., Arnold and Robinson, 2001; Seppälä et al., 2013; Cnossen et al., 2016), and the descent of odd nitrogen (e.g., Randall et al., 2007). To better understand the underlying mechanism, simulations by a climate model covering the entire atmosphere region would be 
helpful, since they may shed light on the impacts of geomagnetic field variations on the dynamics and chemistry of the upper atmosphere to the middle and lower atmosphere. However, the interpretation of whole-atmosphere climate simulations is complicated by the relatively small climate signal in comparison to large climate variability. Hence, an ensemble with adequate samples is needed (the detailed settings in this work are discussed in Section 2). It is also noted that testing the "umbrella effect" is still challenging; although cloud microphysics have been parameterized in the climate model, the relationship to cosmic rays is still under debate.

As a radiatively active greenhouse gas, carbon dioxide $\left(\mathrm{CO}_{2}\right)$ plays a key role in the energy budget of the entire atmosphere. Previous studies have established that $\mathrm{CO}_{2}$ increase produces global warming in the troposphere and cooling in the stratosphere and above, because it absorbs and radiates in the infrared band which becomes optically thin with increasing altitude (Fels et al., 1980; Dickinson, 1984). In particular, the cooling effects of $\mathrm{CO}_{2}$ in the upper atmosphere were first studied by Roble and Dickinson (1989) and confirmed by later studies (e.g., Akmaev and Fomichev, 2000; Akmaev et al., 2006; Qian KY et al., 2006, 2011; Fomichev et al., 2007; Garcia et al., 2007; Marsh et al., 2013; Solomon et al., 2015, 2018). The effects of $\mathrm{CO}_{2}$ change versus geomagnetic field change on the climate of the upper atmosphere and ionosphere have been compared previously (e.g. Cnossen, 2014; Yue XN et al., 2018). Based on the Thermosphere Ionosphere Electrodynamics General Circulation Model (TIEGCM), the two terms are treated as independent factors and then used to estimate their contributions to upper atmospheric and ionospheric climate changes. $\mathrm{CO}_{2}$ in the model is specified as a boundary condition in the lower thermosphere and is uniformly distributed horizontally, although without consideration of the spatial and temporal variability of $\mathrm{CO}_{2}$ in the upper atmosphere. Considering the $\mathrm{CO}_{2}$ variability, Cnossen (2020) analyzed the long-term database of WACCM-X using a modified regression method to examine the impact of $\mathrm{CO}_{2}$ and geomagnetic field changes on upper atmosphere climate change. Based on a whole atmosphere model, GAIA, the $\mathrm{CO}_{2}$ doubling effect in the upper atmosphere and the dependence of geomagnetic activity upon the $\mathrm{CO}_{2}$-driven trend have been investigated recently (Liu HX et al., 2020, 2021). Nonetheless, to our knowledge, the interaction between $\mathrm{CO}_{2}$ change and geomagnetic field variation has not been investigated before. $\mathrm{CO}_{2}$ variability has been confirmed to be coupled with atmospheric dynamics (e.g. Rezac et al., 2015 and references therein), and this could also be affected by geomagnetic field variation. Thus, it is conceivable that changes in the geomagnetic field would influence $\mathrm{CO}_{2}$ distribution and in turn, the energy budget.

In this study, we examine the potential influence of geomagnetic field variations on atmospheric $\mathrm{CO}_{2}$ and its energy budget. We perform several sets of numerical experiments using the Whole Atmosphere Community Climate Model-eXtended (WACCM-X) v2.1. To test the $\mathrm{CO}_{2}$ response, we artificially reduce the strength of the geomagnetic field to $50 \%$ of its original level. This helps us establish whether $\mathrm{CO}_{2}$ would redistribute under such extreme geomagnetic field changes. By controlling for other factors, this whole-atmosphere sensitivity study can reveal the role of the geo- magnetic field in $\mathrm{CO}_{2}$ changes and suggest the corresponding mechanism. To determine whether a measurable effect exists for realistic geomagnetic field changes, we compare the $\mathrm{CO}_{2}$ response to different geomagnetic fields in the past three decades (from 1978 to 2013).

\section{Overviews of WACCM-X and Simulation Setups}

WACCM-X v.2.1 is one of the atmospheric components of the National Center for Atmospheric Research (NCAR) Community Earth System Model (CESM), covering Earth's entire atmosphere extending from the surface to the exobase. Detailed descriptions of WACCM-X can be found in Liu HL et al. (2018). Briefly, the upper boundary of the model is $4.1 \times 10^{-10} \mathrm{hPa}(\sim 500-700 \mathrm{~km}$, depending on solar activity), with one quarter of the scale height resolution in the mesosphere and thermosphere, and a horizontal resolution of $2.5^{\circ} \times 1.9^{\circ}$ (longitude $\times$ latitude). The physics package is based on CAM4 and WACCM4 (Marsh et al., 2013; Neale et al., 2013). High-latitude electric potential and auroral particle precipitation are specified by empirical models (Heelis et al., 1982; Roble and Ridley, 1987). The configurations of the geomagnetic field given by the International Geomagnetic Reference Field (IGRF) (Thébault et al., 2015) and electrodynamic processes are calculated based on the Magnetic Apex coordinate (Richmond, 1995). In WACCM-X, local thermodynamic equilibrium (LTE) and non-LTE processes are considered for different altitudes; these processes are defined in detail by Andrews et al. (1987). Below the mesosphere and lower thermosphere (MLT) region, the standard longwave formulation in CAM is used; in the region between 85$110 \mathrm{~km}$, as the atmospheric density decreases, non-LTE effects strengthen and are calculated using the recurrence formula in Fomichev et al. (1998). Above $110 \mathrm{~km}$, as in TIEGCM, the coolingto-space approximation is assumed. This implies that the radiative cooling of a given atmospheric layer is controlled by the emission directly cooling to space, while the exchange from above and below is offset and therefore can be ignored (Jeevanjee and Fueglistaler, 2020). In addition, horizontal variability of $\mathrm{CO}_{2}$ concentration is considered to be coupled with neutral dynamics. The more comprehensive consideration of the $\mathrm{CO}_{2}$ cooling term in WACCM$X$ enables us to study its response to geomagnetic field variations from the thermosphere down to the mesosphere.

To investigate whether $\mathrm{CO}_{2}$ would be affected by geomagnetic field variations, other external forces should be held constant: specifically, solar activity ( $F=70 \mathrm{sfu}$.) and geomagnetically quiet conditions $(K p=2)$. To exclude inter-annual variability from below, anthropogenic emissions and sea surface temperature at the lower boundary are set as the average condition around the year of 2000 . To more clearly identify the signal over the large variability of the system, we artificially reduce the strength of the geomagnetic field to $50 \%$ of the original level (base case) and keep the inclination and declination angle constant by modifying the IGRF coefficients in the model. The two cases are called half- $B$ control and original-B base case, hereafter. To enlarge the signal in the simulations, we chose to set $K p=2$ rather than use an extreme quiet condition; e.g. 0.33. 100-year continuous simulations are performed for each case to form ensembles with samples large enough for statistical analysis. Notably, although external 
forces are kept constant in the 100-year perpetual runs, the atmospheric state is different for each year due to internal atmospheric variability. Figure S1 depicts the variations of zonal mean temperature from January to March in the original-B case. The standard deviation of zonal mean temperature among the ensembles is $\sim 1-3 \mathrm{~K}$, which is comparable to the magnitude of day-to-day variability for an individual sample. The result indicates that the runs do in fact generate statistics in the ensembles. Although this hypothetical change of geomagnetic fields is large in comparison to the geomagnetic dipole moment, which decreases at a rate of $\sim 5 \%$ on century scales (Gubbins et al., 2006), it could still be valuable for studies on the paleoclimate time scale. For instance, a Holocene geomagnetic field model, CASL10k, demonstrates that the dipole moment varies from $\sim 6 \times 10^{22}$ to $1 \times 10^{23} \mathrm{Am}^{2}$ spanning the past 10 kys (Korte et al., 2011; Constable et al., 2016). For the past several million years, analysis of paleomagnetic records indicates that the strength of the geomagnetic dipole moment could diminish to below $2 \times 10^{22} \mathrm{Am}^{2}$ (Valet and Meynadier, 1993; Guyodo and Valet, 1999). This simulation is also beneficial for investigating how deep the impact of such extreme changes may extend from the upper atmosphere to the middle atmosphere.

To examine the effect of realistic geomagnetic condition changes during the modern era, we carry out two additional sets of simulations. These are time-slice simulations (Solomon et al., 2018) with the anthropogenic emission rates set at current-day levels (2011-2015), compared to historic geomagnetic fields, specifically for 1978 vs. 2013 (labeled B1978 and B2013 hereafter). Figure S2 shows the geomagnetic intensity, inclination angle, and declination angle in the two configurations and their respective differences. Each case continuously runs 5 years after a 1-year spin-up. The 5-year interval forms a small ensemble to reduce the impact of inter-annual variability. Concentrations of anthropogen- ic gases are specified by the historical time-dependent lower boundary condition.

\section{Results and Discussion}

As shown in Figures $1 \mathrm{a}-1 \mathrm{c}$, zonal mean $\mathrm{CO}_{2}$ volume mixing ratios (VMRs) of the half-B case increase by $\sim 3-10$ ppmv at high latitudes for different seasons and decrease by $\sim 2$ ppmv at low latitudes and the equator in the lower thermosphere $(\sim 100$ to $150 \mathrm{~km}$ ), compared with the original-B case. In the summer hemisphere, the increase of $\mathrm{CO}_{2}$ is larger than that in the winter hemisphere, and the former has double peaks at $\sim 8.9 \times 10^{-6} \mathrm{hPa}$ $(\sim 140 \mathrm{~km})$ and $1.4 \times 10^{-4} \mathrm{hPa}(\sim 103 \mathrm{~km})$, whereas the latter has only one peak at $\sim 8.9 \times 10^{-6} \mathrm{hPa}(\sim 140 \mathrm{~km})$. The student's $t$-test is used to calculate the statistical significance of these differences. The increase of $\mathrm{CO}_{2}$ in the summer hemisphere due to the change of geomagnetic fields can extend to the mesosphere $(\sim 1.7 \times$ $\left.10^{-3} \mathrm{hPa}, \sim 88 \mathrm{~km}\right)$ relative to the winter hemisphere $(\sim 2.4 \times$ $10^{-5} \mathrm{hPa}, \sim 115 \mathrm{~km}$ ), with $99 \%$ statistical significance level ( $p$ value is 0.01 ). As a comparison, the anthropogenic change in $\mathrm{CO}_{2}$ over past decades in the mesosphere and the lower thermosphere is $\sim 5.5 \%$ per decade (Qian LY et al., 2017), which is approximately 5-10 ppmv per decade at the pressure levels of $10^{-4}$ to $10^{-3} \mathrm{hPa}$.

Differences in $\mathrm{CO}_{2}$ cooling rates between the half- $\mathrm{B}$ and original- $\mathrm{B}$ cases are depicted in Figures $1 \mathrm{~d}-1 \mathrm{f}$, which denotes different features from the change of $\mathrm{CO}_{2}$ VMRs. As the geomagnetic field weakens, $\mathrm{CO}_{2}$ cooling increases by $\sim 2-4 \mathrm{~K} /$ day above $\sim 100 \mathrm{~km}$, with a larger value for high latitudes and a smaller value for middle and low latitudes. Below $\sim 100 \mathrm{~km}, \mathrm{CO}_{2}$ cooling weakened slightly at high latitudes in summer, and in both hemispheres during equinoxes. The response of $\mathrm{CO}_{2}$ cooling to the weakening geomagnetic field is also deeper in the summer hemisphere,

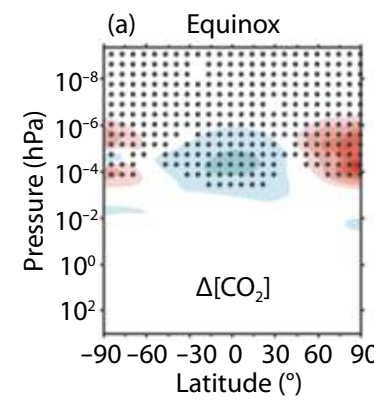

(d)

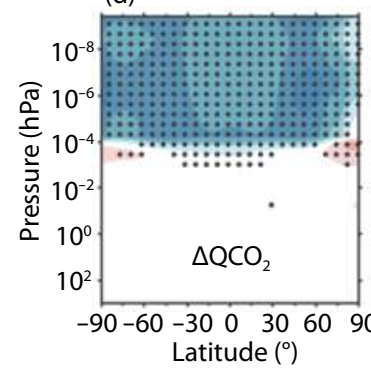

(b) Nov-Feb

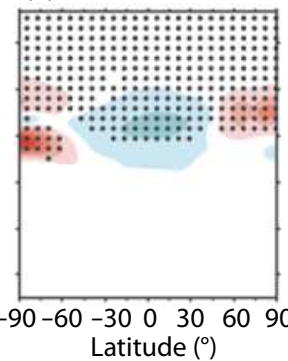

(e)

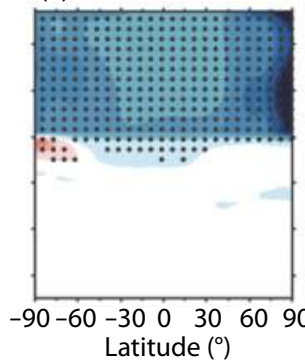

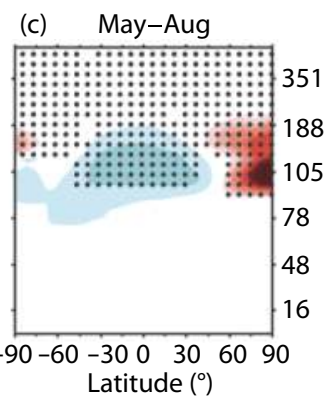

(f)

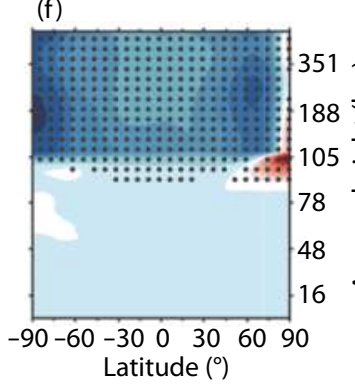

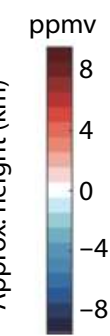

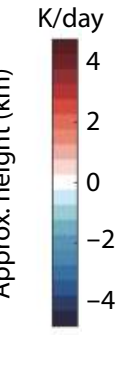

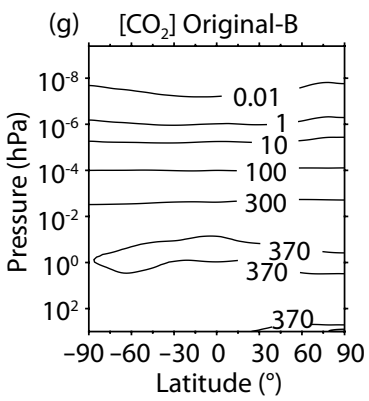

(h) $\mathrm{QCO}_{2}$ Original-B

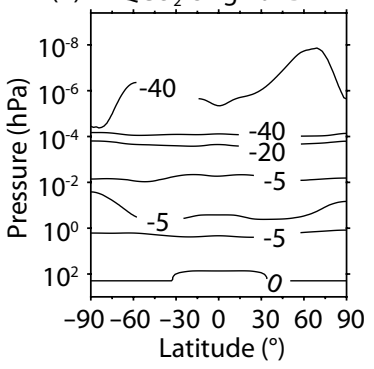

Figure 1. Differences in the zonal mean (top row) mixing ratio and (bottom row) heating rate of $\mathrm{CO}_{2}$ in (left) equinox, (middle) northern winter, and (right) northern summer. The grey dots indicate the area where the differences are $99 \%$ statistically significant. The approximate height of the corresponding pressure level is labeled on the right. The subplots $(\mathrm{g})$ and $(\mathrm{h})$ contour the zonal mean $\mathrm{CO}_{2} \mathrm{VMR}$ and $\mathrm{CO}_{2}$ cooling rates during equinox for the original-B case, respectively. 
whereas the cooling rate decreases more in the winter hemisphere; this was statistically significant using the student's $t$-test. The enhanced cooling effect in the thermosphere is stronger in the winter hemisphere than in the summer hemisphere. Notably, the $\mathrm{CO}_{2}$ cooling is not only dependent on its abundance, but is also determined by temperature and atomic oxygen $(\mathrm{O})$ abundance. In the thermosphere, the temperature significantly increases due to enhanced Joule heating. The corresponding change of $\mathrm{O}$ is shown in Figure $\mathrm{S} 3$, decreasing over $0.15 \mathrm{~mol} / \mathrm{mol}$ at high latitudes and increasing $\sim 0.02 \mathrm{~mol} / \mathrm{mol}$ at low latitudes. The relative decrease in O VMRs reaches a maximum of $\sim 20 \%$ for high latitudes at the height of $\sim 150 \mathrm{~km}$. The zonal mean $\mathrm{CO}_{2} \mathrm{VMR}$ and $\mathrm{CO}_{2}$ cooling rate during the equinox for the original- $\mathrm{B}$ case are shown in Figures $1 \mathrm{~g}$ and $1 \mathrm{~h}$. The changed $\mathrm{CO}_{2} \mathrm{VMR}$ at high latitudes is about $1-10 \%$ for the height of $90-200 \mathrm{~km}$, and the changed $\mathrm{CO}_{2}$ cooling rate is $\sim 5-10 \%$ throughout the thermosphere.

Figure 2a compares the magnitude change of global mean $\mathrm{CO}_{2}$ cooling rates with other important energy sources/sinks, and the corresponding heating/cooling rates in the original case are shown in Figure $2 \mathrm{~b}$ as a reference. Joule heating is the dominant energy source that differs between half- $B$ and original- $B$ cases above $\sim 115 \mathrm{~km}$. lonospheric conductivity is inversely proportional to the strength of the geomagnetic field (Cnossen et al., 2012), and the Joule heating rate is proportional to Pedersen conductivity. Thus, a weak geomagnetic field leads to stronger Joule heating for the thermosphere. In response to increased Joule heating, nitric oxide (NO) plays a more important role in cooling the thermosphere at $5.3 \mu \mathrm{m}$ (e.g., Kockarts, 1980), because the NO cooling rate is sensitive to temperature and quickly reacts to energy inputs, serving as a "natural thermostat" for the thermosphere (e.g., Mlynczak et al., 2003, 2018; Lu G et al., 2010). This is seen in Figure 2a: the change of $\mathrm{NO}$ cooling is the dominant term from $\sim 115 \mathrm{~km}$ to $220 \mathrm{~km}$ and is over $-20 \mathrm{~K} /$ day at the peak ( 100\%). A detailed comparison of NO VMRs and corresponding cooling effects is shown in Figure 4. Generally, $\mathrm{CO}_{2}$ ceases to be important in the heat budget of the lower thermosphere above $\sim 140 \mathrm{~km}$ (Mlynczak et al., 2018). In this case, $\mathrm{CO}_{2}$ cooling increases by $\sim 2 \mathrm{~K} /$ day throughout the thermosphere above $\sim 105 \mathrm{~km}(\sim 5 \%)$ when the geomagnetic field weakens. Between $100-110 \mathrm{~km}, \mathrm{CO}_{2}$ is the primary changed cooling agent. The change in another cooling term, $\mathrm{O}(3 \mathrm{P})$ cooling at $63 \mu \mathrm{m}$, is relatively insignificant (less than $\pm 2 \mathrm{~K} /$ day for all altitudes).

As a trace species with a long lifetime, the transport of $\mathrm{CO}_{2}$ and its
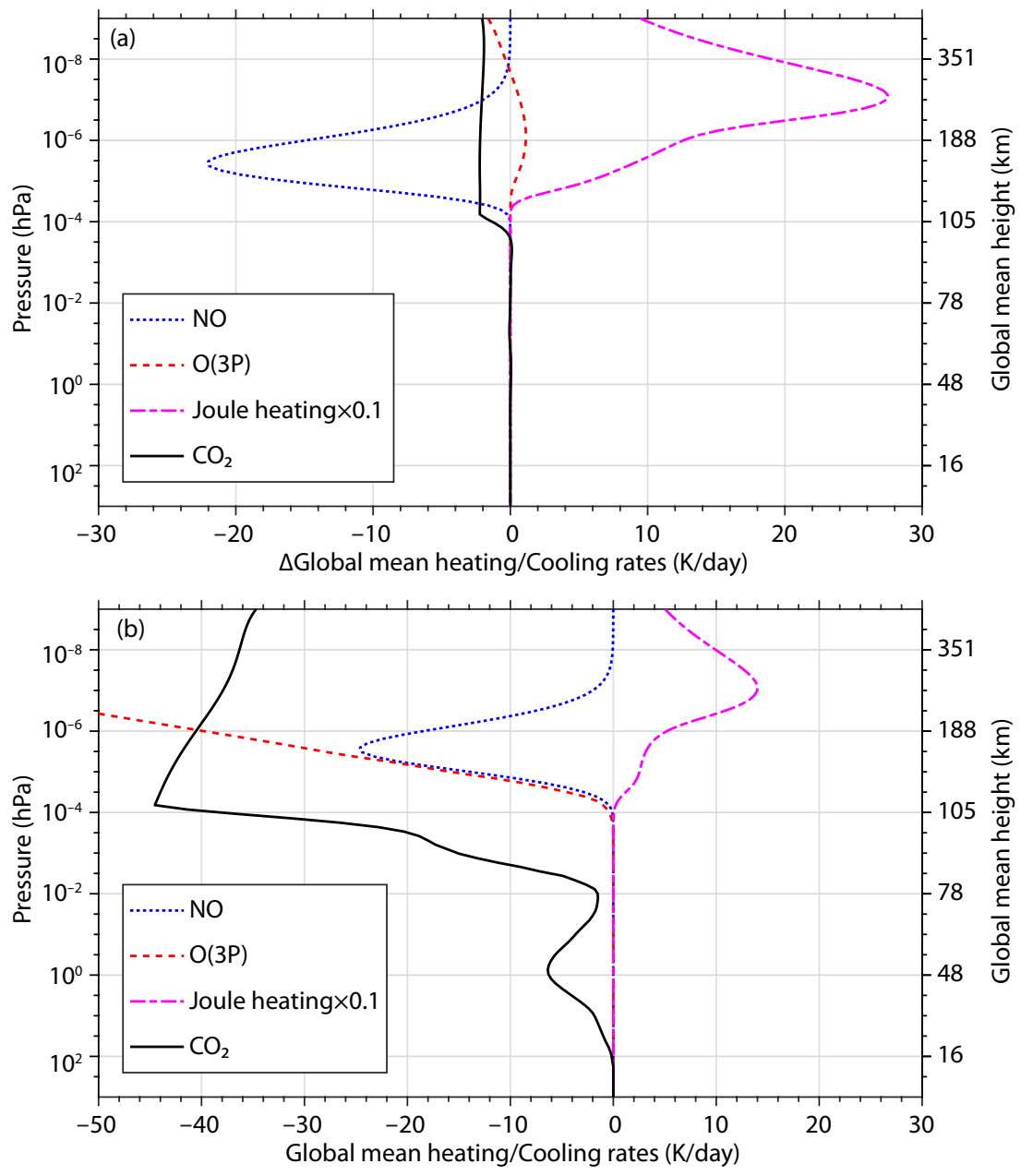

Figure 2. (a) The difference in global mean heating rates for $\mathrm{CO}_{2}$ (black solid), $\mathrm{NO}$ (blue dotted), $\mathrm{O}(3 \mathrm{P}$ ) (red dash), and Joule heating divided by a factor of 10 (magenta dash-dot) between half-B and original-B cases in December. Subplot (b) is for the four heating/cooling sources in the original-B case displayed here for comparison. The right axis presents the global mean height as a reference. 
spatial distribution in the mesosphere is determined by atmospheric general circulation, which is quantified by the residual mean circulation (Andrews and Mcintyre, 1976, Andrews et al., 1987). The meridional and vertical components of the residual mean circulation, $\overline{v^{*}}$ and $\overline{w^{*}}$, are expressed as follows:

$$
\begin{gathered}
\overline{v^{*}}=\bar{v}-\frac{1}{\rho_{0}}\left(\rho_{0} \frac{\overline{v^{\prime} \theta^{\prime}}}{\overline{\theta_{z}}}\right)_{z} \\
\overline{w^{*}}=\bar{w}+(a \cos \varphi)^{-1}\left(\cos \varphi \frac{\overline{v^{\prime} \theta^{\prime}}}{\theta_{z}}\right)_{\varphi}
\end{gathered}
$$

where $z$ is the log-pressure altitude, defined as $z=-H_{0} \log \left(p / p_{\mathrm{s}}\right)$.
$H_{0}$ is the constant approximate scale height of $7 \mathrm{~km}$, and $p_{\mathrm{s}}$ is the mean surface pressure. $\bar{v}$ and $\bar{w}$ are the zonal mean meridional and vertical velocity, respectively. $a$ is the Earth's mean radius of $6371 \mathrm{~km}, \varphi$ is latitude, and $\theta$ is the potential temperature. $\rho_{0}$ is the basic density, defined by $\rho_{0}=p / R T_{\mathrm{s}}$, where $R$ is the gas constant of $287 \mathrm{~J} / \mathrm{kg} / \mathrm{K}$, and $T_{\mathrm{s}}$ is mean surface temperature. The notation of prime indicates a departure from zonal mean fields.

Figure 3a displays the residual circulation averaged from 100 model years of the original-B case during the solstice month of June. The clear summer to winter circulation includes a strong upward/southward motion at the summer pole and downward/ southward motion at the winter pole below $\sim 90 \mathrm{~km}$ and above

(a) Residual circulation in JUN; Original-B

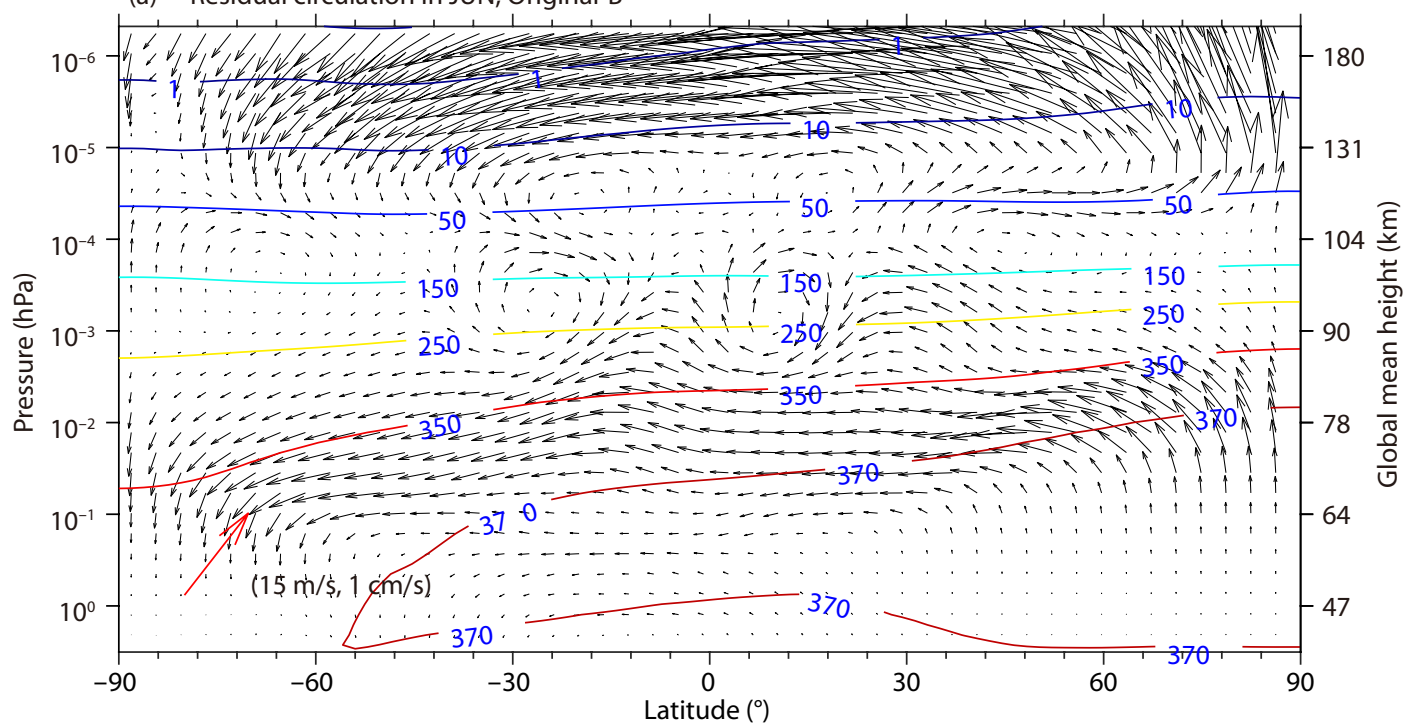

(b) $\Delta$ Normalized residual circulation in JUN

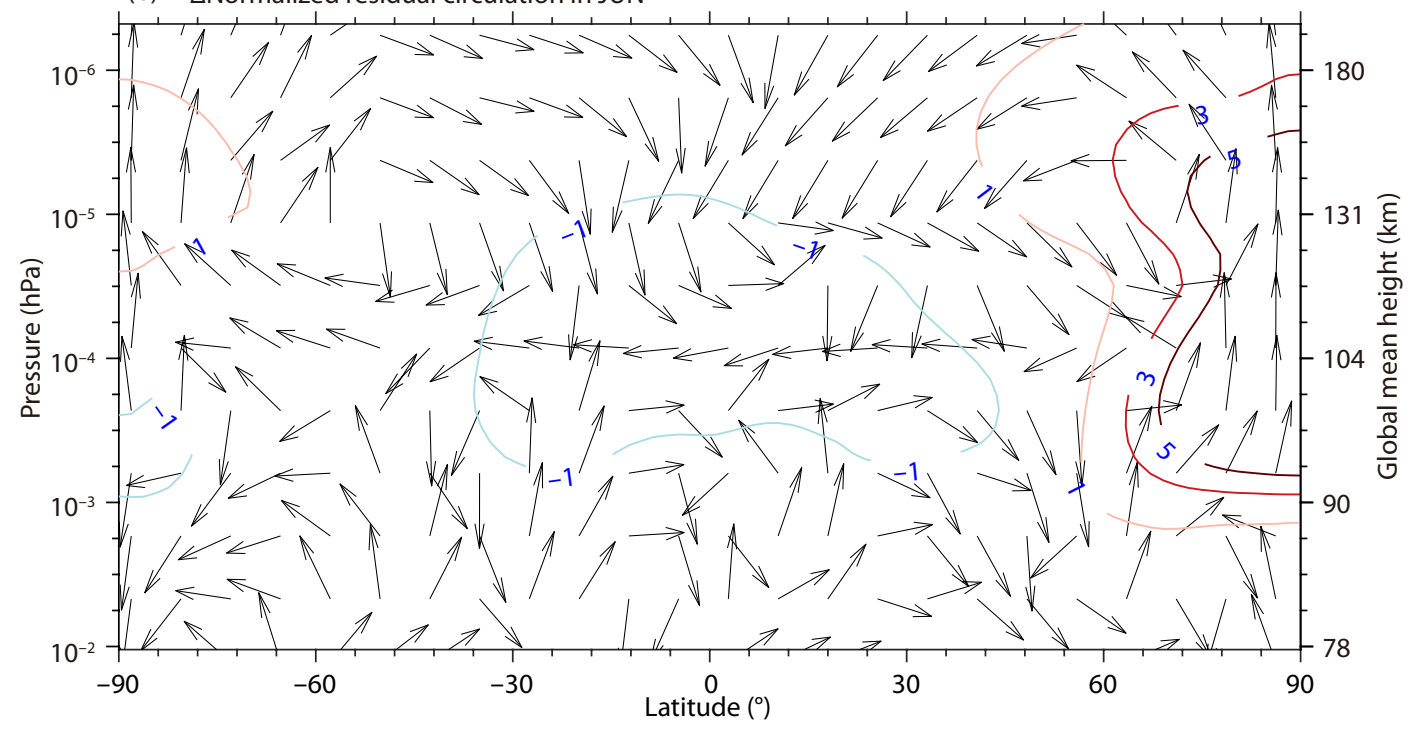

Figure 3. (a) Residual circulation for the original-B case in June averaged across all members of the ensemble. The contour lines show corresponding zonal mean VMRs of $\mathrm{CO}_{2}$. The horizontal and vertical projections of the red vector displayed on the bottom left corner indicate the scale of $15 \mathrm{~m} / \mathrm{s}$ for meridional and $1 \mathrm{~cm} / \mathrm{s}$ for upward velocity. (b) Differences in normalized residual circulation between the half-B and original-B case in June. The contour lines show corresponding differences in zonal mean VMRs of $\mathrm{CO}_{2}$. The right $y$-axis indicates the global mean height as a reference. 

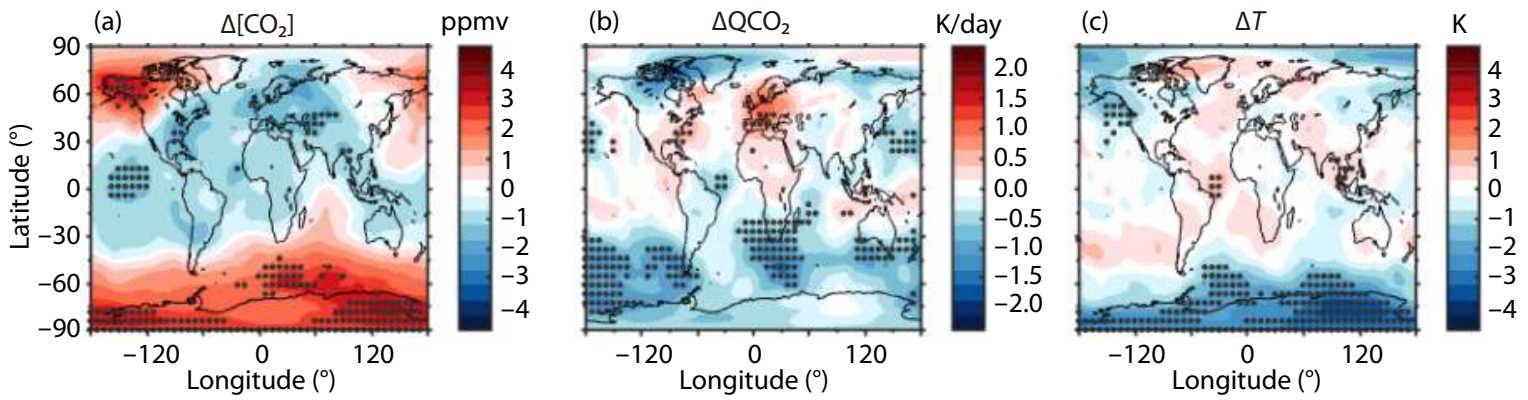

Figure 4. Differences in (a) VRM of $\mathrm{CO}_{2}$, (b) $\mathrm{CO}_{2}$ heating rates, and (c) temperature between $\mathrm{B} 2013$ and $\mathrm{B} 1978$ cases averaged for winter (November to February) at a pressure level of $6.6 \times 10^{-5} \mathrm{hPa}(\sim 110 \mathrm{~km})$. The gray dots indicate the area where the differences are statistically significant at a $90 \%$ level. The black lines are continental coastlines.

$110 \mathrm{~km}$. The primary driver of the summer to winter circulation in the mesosphere/mesopause region is gravity wave forcing. In the region between the altitudes, there are several clockwise rotation cells with weak upward motion in winter and downward motion in summer at high latitudes, which are also driven by gravity wave forcing; this flow pattern is consistent with Fig. 1 in Smith et al. (2011). The opposing circulations below and above $90 \mathrm{~km}$ lead to the vertical gradient of $\mathrm{CO}_{2}$ being larger in the summer hemisphere than the winter hemisphere around the mesopause, as shown by the contour lines in Figure 3a. To illustrate the effect on the residual circulations caused by the weakening geomagnetic field, Figure $3 \mathrm{~b}$ displays the differences in residual circulation between half-B and original-B cases, normalized to unit vector length, in the same month of June in the region where the change of $\mathrm{CO}_{2}$ VMRs is large. It also presents the corresponding differences of the $\mathrm{CO}_{2}$ VMRs in contour lines. Normalizing the wind vector better illustrates the flow direction at all altitudes. The strong enhanced upward/equatorward circulation above $\sim 105 \mathrm{~km}$ is found at high latitudes in both hemispheres, with downward flow at mid and low latitudes. This change is caused by enhanced Joule heating rates above $115 \mathrm{~km}$. Consequently, upwelling at high latitudes could bring $\mathrm{CO}_{2}$-rich air from below, and downwelling at mid and low latitudes transports $\mathrm{CO}_{2}$ from the thermosphere where it is rare. The increased upward flow extends to $\sim 90 \mathrm{~km}$ and $\sim 100 \mathrm{~km}$ in the summer and winter hemispheres, respectively. In addition, the vertical gradient of $\mathrm{CO}_{2}$ is generally larger in the summer hemisphere (contour lines in Figure 3a) such that upwelling in this hemisphere brings more $\mathrm{CO}_{2}$ from below, increasing $\mathrm{CO}_{2}$ VMRs (Figures $1 \mathrm{~b}$ and $1 \mathrm{c}$ ).

Figure 4 illustrates the differences among $\mathrm{CO}_{2}$ VMRs, $\mathrm{CO}_{2}$ cooling rates, and neutral temperature between the B2013 and B1978 cases with realistic changes in the geomagnetic field for the northern winter at a pressure level of $6.6 \times 10^{-5} \mathrm{hPa}(\sim 110 \mathrm{~km})$. Significant enhancement of $\mathrm{CO}_{2}$ VMRs is found at high latitudes ( 3-4 ppmv), especially in the southern hemisphere where the intensity of the geomagnetic field is consistently smaller in 2013 than in 1978 (Figure S1d). At mid and low latitudes, $\mathrm{CO}_{2}$ VMRs decrease by $\sim 1-2$ ppmv. Correspondingly, the $\mathrm{CO}_{2}$ cooling rate increases at high latitudes by $\sim 2 \mathrm{~K} /$ day and decreases at mid and low latitudes by $\sim 1 \mathrm{~K} /$ day. As for neutral temperature changes, this significantly increases above $\sim 115 \mathrm{~km}$ due to enhanced Joule heating. Below this region dominated by Joule heating, the cool- ing effect becomes important. Figure $4 \mathrm{c}$ indicates that the neutral temperature changes at $\sim 110 \mathrm{~km}$, which decreases by $\sim 2-3 \mathrm{~K}$ at high latitudes in the southern hemisphere with statistical significance. This temperature decrease should also be influenced by another important cooling effect: enhanced upwelling induced adiabatic cooling (Li JY et al., 2018, 2019). The relative contribution of the dynamic effect and $\mathrm{CO}_{2}$ radiative effect need to be further studied in detail, although the latter seems to be small according to our analysis. Retrospective comparison between half-B and Original-B cases in Figure 2 confirms that $\mathrm{NO}$ cools the atmosphere above $\sim 110 \mathrm{~km}$, but is not the dominant factor of the energy budget at 100-110 km. In addition, compared with $\mathrm{CO}_{2}$ changes between half- $\mathrm{B}$ and original- $\mathrm{B}$ cases, the magnitude of the $\mathrm{CO}_{2}$ difference for B2013 is $\sim 30 \%$ less than B1978, whereas the corresponding geomagnetic dipole moment decreases only by $\sim 2 \%$, which is $\sim 1 / 25$ of the $50 \%$ change found in the former experiments. This inconsistency in magnitude may be partially caused by three reasons: (a) B2013 and B1978 cases include larger atmospheric interannual variability, and half- $\mathrm{B}$ and original-B cases are perpetually run for the year 2000; (b) a large number of members in half- $B$ and original- $B$ would reduce the effect of atmospheric internal variability; and (c) changes in circulation between B2013 and B1978 cases should be more complex because the inclination and declination angles of the geomagnetic field are also different. The nonlinear response of $\mathrm{CO}_{2}$ VMR to the change in geomagnetic field intensity is another interesting factor that prompts future investigation.

Although we did not determine whether surface climate would change due to geomagnetic field variation in the present work, according to the known physics included in WACCM-X which lacks a coupling ocean, a large geomagnetic field change can have effects down to the mesosphere, but no significant change below that (Figure 1). $\mathrm{CO}_{2}$ changes in the middle and upper mesosphere presented here might provide a progressive insight that geomagnetic field variation could influence neutral dynamics, distribution of neutral compositions, and thermal structure of the middle atmosphere. When considering other possible factors related to the geomagnetic field (cosmic rays and particle precipitation, etc.), and more extreme geomagnetic conditions (e.g. polarity reversals), in the future the $\mathrm{CO}_{2}$ and temperature responses might be expected to be larger and may even reach lower altitudes. 


\section{Conclusion}

In this study, $\mathrm{CO}_{2}$ distribution responses to changes in the geomagnetic field are investigated based on WACCM-X simulations. An artificially extreme experiment reducing geomagnetic field strength to $50 \%$ of the original level illustrates that the response exists in the atmosphere above $\sim 90 \mathrm{~km}$ with $99 \%$ statistical significance. $\mathrm{CO}_{2}$ VMRs increase at high latitudes and decrease elsewhere. $\mathrm{CO}_{2}$ changes significantly determine the energy budget at $\sim 100-110 \mathrm{~km}$. We propose that the changed transformed Eulerian mean (TEM) circulation and the associated increased Joule heating are responsible for these $\mathrm{CO}_{2}$ changes. Another experiment based on realistic geomagnetic field changes between 1978 and 2013 demonstrated that such an effect is still tenable, indicating that the linkage persists on a time scale of decades. This paper reveals for the first time that $\mathrm{CO}_{2}$ distribution may be influenced by geomagnetic variation, and that climate change may be induced by secular variations in geomagnetic fields.

\section{Acknowledgement}

This work was supported by the B-type Strategic Priority Program of the Chinese Academy of Sciences (Grant No. XDB41000000), the National Natural Science Foundation of China (41621004, 41427901), the Open Research Project of Large Research Infrastructures - "Study on the interaction between low/mid-latitude atmosphere and ionosphere based on the Chinese Meridian Project", and the Key Research Program of the IGGCAS with Grant No. IGGCAS-201904. XZ thanks the UCAS Joint PhD Training Program. The National Center for Atmospheric Research is a major facility sponsored by the National Science Foundation under Cooperative Agreement No. 1852977. WACCM-X and CESM code is available at https://zenodo.org/record/3991447\#.XzzU836-mpo.

\section{References}

Akmaev, R. A., and Fomichev, V. I. (2000). A model estimate of cooling in the mesosphere and lower thermosphere due to the $\mathrm{CO}_{2}$ increase over the last 3-4 decades. Geophys. Res. Lett., 27(14), 2113-2116. https://doi.org/10.1029/1999GL011333

Akmaev, R. A., Fomichev, V. I., and Zhu, X. (2006). Impact of middle-atmospheric composition changes on greenhouse cooling in the upper atmosphere. $J$. Atmos. Solar Terr. Phys., 68(17), 1879-1889. https://doi.org/10.1016/j.jastp.2006.03.008

Andrews, D. G., and Mcintyre, M. E. (1976). Planetary waves in horizontal and vertical shear: the generalized Eliassen-Palm relation and the mean zonal acceleration. J. Atmos. Sci., 33(11), 2031-2048. https://doi.org/10.1175/15200469(1976)033<2031:PWIHAV>2.0.CO;2

Andrews, D. G., Holton, J. R., and Leovy, C. B. (1987). Middle Atmosphere Dynamics (pp. 128). San Diego: Academic Press.

Arnold, N. F., and Robinson, T. R. (2001). Solar magnetic flux influences on the dynamics of the winter middle atmosphere. Geophys. Res. Lett., 28(12), 2381-2384. https://doi.org/10.1029/2000GL012825

Cnossen, I., Richmond, A. D., Wiltberger, M., Wang, W. B., and Schmitt, P. (2011). The response of the coupled magnetosphere-ionosphere-thermosphere system to a $25 \%$ reduction in the dipole moment of the Earth's magnetic field. J. Geophys. Res., 116(A12), A12304. https://doi.org/10.1029/2011JA017063

Cnossen, I., Richmond, A. D., and Wiltberger, M. (2012). The dependence of the coupled magnetosphere-ionosphere-thermosphere system on the Earth's magnetic dipole moment. J. Geophys. Res., 117(A5), A05302. https://doi.org/10.1029/2012JA017555

Cnossen, I., and Richmond, A. D. (2012). How changes in the tilt angle of the geomagnetic dipole affect the coupled magnetosphere-ionospherethermosphere system. J. Geophys. Res., 117(A10), A10317. https://doi.org/10.1029/2012JA018056

Cnossen, I. (2014). The importance of geomagnetic field changes versus rising $\mathrm{CO}_{2}$ levels for long-term change in the upper atmosphere. J. Space Wea. Space Climate, 4, A18. https://doi.org/10.1051/swsc/2014016

Cnossen, I., Liu, H. L., and Lu, H. (2016). The whole atmosphere response to changes in the Earth's magnetic field from 1900 to 2000: an example of "top-down" vertical coupling. J. Geophys. Res., 121(13), 7781-7800. https://doi.org/10.1002/2016JD024890

Cnossen, I. (2020). Analysis and attribution of climate change in the upper atmosphere from 1950 to 2015 simulated by WACCM-X. J. Geophys. Res., 125(12), e2020JA028623. https://doi.org/10.1029/2020JA028623

Constable, C., Korte, M., and Panovska, S. (2016). Persistent high paleosecular variation activity in southern hemisphere for at least 10000 years. Earth Planet. Sci. Lett., 453, 78-86. https://doi.org/10.1016/j.epsl.2016.08.015

De Santis, A., Qamili, E., Spada, G., and Gasperini, P. (2012). Geomagnetic South Atlantic Anomaly and global sea level rise: a direct connection?. J. Atmos. Solar Terr. Phys., 74, 129-135. https://doi.org/10.1016/j.jastp.2011.10.015

Dickinson, R. E. (1984). Infrared radiative cooling in the mesosphere and lower thermosphere. J. Atmos. Terr. Phys., 46(11), 995-1008. https://doi.org/10.1016/0021-9169(84)90006-0

Fels, S. B., Mahlman, J. D., Schwarzkopf, M. D., and Sinclair, R. W. (1980). Stratospheric sensitivity to perturbations in ozone and carbon dioxide: radiative and dynamical response. J. Atmos. Sci., 37(10), 2265-2297. https://doi.org/10.1175/1520-0469(1980)037<2265:SSTPIO>2.0.CO;2

Fomichev, V. I., Blanchet, J. P., and Turner, D. S. (1998). Matrix parameterization of the $15 \mu \mathrm{m} \mathrm{CO}_{2}$ band cooling in the middle and upper atmosphere for variable $\mathrm{CO}_{2}$ concentration. J. Geophys. Res., 103(D10), 11505-11528. https://doi.org/10.1029/98JD00799

Fomichev, V. I., Jonsson, A. I., de Grandpré, J., Beagley, S. R., McLandress, C., Semeniuk, K., and Shepherd, T. G. (2007). Response of the middle atmosphere to $\mathrm{CO}_{2}$ doubling: results from the Canadian middle atmosphere model. J. Climate, 20(7), 1121-1144. https://doi.org/10.1175/JCLI4030.1

Gallet, Y., Genevey, A., and Fluteau, F. (2005). Does Earth's magnetic field secular variation control centennial climate change?. Earth Planet. Sci. Lett., 236(1-2), 339-347. https://doi.org/10.1016/j.epsl.2005.04.045

Garcia, R. R., Marsh, D. R., Kinnison, D. E., Boville, B. A., and Sassi, F. (2007). Simulation of secular trends in the middle atmosphere, 1950-2003. J. Geophys. Res., 112(D9), D09301. https://doi.org/10.1029/2006JD007485

Gubbins, D., Jones, A. L., and Finlay, C. C. (2006). Fall in Earth's magnetic field is erratic. Science, 312(5775), 900-902. https://doi.org/10.1126/science.1124855

Guyodo, Y., and Valet, J. P. (1999). Global changes in intensity of the Earth's magnetic field during the past 800 kyr. Nature, 399(6733), 249-252. https://doi.org/10.1038/20420

Heelis, R. A., Lowell, J. K., and Spiro, R. W. (1982). A model of the high-latitude ionospheric convection pattern. J. Geophys. Res., 87(A8), 6339-6345. https://doi.org/10.1029/JA087iA08p06339

Jeevanjee, N., and Fueglistaler, S. (2020). On the cooling-to-space approximation. J. Atmos. Sci., 77(2), 465-478. https://doi.org/10.1175/JAS-D18-0352.1

Kitaba, I., Hyodo, M., Katoh, S., Dettman, D. L., and Sato, H. (2013). Midlatitude cooling caused by geomagnetic field minimum during polarity reversal. Proc. Natl. Acad. Sci. USA, 110(4), 1215-1220. https://doi.org/10.1073/pnas.1213389110

Kitaba, I., Hyodo, M., Nakagawa, T., Katoh, S., Dettman, D. L., and Sato, H. (2017). Geological support for the umbrella effect as a link between geomagnetic field and climate. Sci. Rep., 7, 40682. https://doi.org/10.1038/srep40682

Kockarts, G. (1980). Nitric oxide cooling in the terrestrial thermosphere. Geophys. Res. Lett., 7(2), 137-140. https://doi.org/10.1029/GL007i002p00137

Korte, M., Constable, C., Donadini, F., and Holme, R. (2011). Reconstructing the Holocene geomagnetic field. Earth Planet. Sci. Lett., 312(3-4), 497-505. https://doi.org/10.1016/j.epsl.2011.10.031

Li, J. Y., Wang, W. B., Lu, J. Y., Yuan, T., Yue, J., Liu, X., Zhang, K. D., Burns, A. G., Zhang, Y. L., and Li, Z. (2018). On the responses of mesosphere and lower 
thermosphere temperatures to geomagnetic storms at low and middle latitudes. Geophys. Res. Lett., 45(19), 10128-10137.

https://doi.org/10.1029/2018GL078968

Li, J. Y., Wang, W. B., Lu, J. Y., Yue, J., Burns, A. G., Yuan, T., Chen, X. T., and Dong, W. J. (2019). A modeling study of the responses of mesosphere and lower thermosphere winds to geomagnetic storms at middle latitudes. J. Geophys. Res., 124(5), 3666-3680. https://doi.org/10.1029/2019JA026533

Liu, H. L., Bardeen, C. G., Foster, B. T., Lauritzen, P., Liu, J., Lu, G., Marsh, D. R., Maute, A., Mcinerney, J. M., ... Wang, W. B. (2018). Development and validation of the whole atmosphere community climate model with thermosphere and ionosphere extension (WACCM-X 2.0). J. Adv. Model. Earth Syst., 10(2), 381-402. https://doi.org/10.1002/2017MS001232

Liu, H. X., Tao, C., Jin, H., and Nakamoto, Y. (2020). Circulation and tides in a cooler upper atmosphere: dynamical effects of $\mathrm{CO}_{2}$ doubling. Geophys. Res. Lett., 47(10), e2020GL087413. https://doi.org/10.1029/2020GL087413

Liu, H. X., Tao, C., Jin, H., and Abe, T. (2021). Geomagnetic activity effects on $\mathrm{CO}_{2}$-driven trend in the thermosphere and ionosphere: ideal model experiments with GAIA. J. Geophys. Res., 126(1), e2020JA028607. https://doi.org/10.1029/2020JA028607

Lu, G., Mlynczak, M. G., Hunt, L. A., Woods, T. N., and Roble, R. G. (2010). On the relationship of Joule heating and nitric oxide radiative cooling in the thermosphere. J. Geophys. Res., 115(A5), A05306. https://doi.org/10.1029/2009JA014662

Marsh, D. R., Mills, M. J., Kinnison, D. E., Lamarque, J. F., Calvo, N., and Polvani, L. M. (2013). Climate change from 1850 to 2005 simulated in CESM1(WACCM). J. Climate, 26(19), 7372-7391. https://doi.org/10.1175/JCLI-D-12-00558.1

Mlynczak, M., Martin-Torres, F. J., Russell, J., Beaumont, K., Jacobson, S., Kozyra, J., Lopez-Puertas, M., Funke, B., Mertens, C., ... Paxton, L. (2003). The natural thermostat of nitric oxide emission at $5.3 \mu \mathrm{m}$ in the thermosphere observed during the solar storms of April 2002. Geophys. Res. Lett., 30(21), 2100. https://doi.org/10.1029/2003GL017693

Mlynczak, M. G., Knipp, D. J., Hunt, L. A., Gaebler, J., Matsuo, T., Kilcommons, L. M., and Young, C. L. (2018). Space-based sentinels for measurement of infrared cooling in the thermosphere for space weather nowcasting and forecasting. Space Wea., 16(4), 363-375. https://doi.org/10.1002/2017SW001757

Neale, R. B., Richter, J., Park, S., Lauritzen, P. H., Vavrus, S. J., Rasch, P. J., and Zhang, M. H. (2013). The mean climate of the Community Atmosphere Model (CAM4) in forced SST and fully coupled experiments. J. Climate, 26(14), 5150-5168. https://doi.org/10.1175/JCLI-D-12-00236.1

Qian, L. Y., Roble, R. G., Solomon, S. C., and Kane, T. J. (2006). Calculated and observed climate change in the thermosphere, and a prediction for solar cycle 24. Geophys. Res. Lett., 33(23), L23705. https://doi.org/10.1029/2006GL027185

Qian, L. Y., Laštovička, J., Roble, R. G., and Solomon, S. C. (2011). Progress in observations and simulations of global change in the upper atmosphere. J. Geophys. Res., 116(A2), A00H03. https://doi.org/10.1029/2010JA016317

Qian, L. Y., Burns, A. G., Solomon, S. C., and Wang, W. B. (2017). Carbon dioxide trends in the mesosphere and lower thermosphere. J. Geophys. Res., 122(4), 4474-4488. https://doi.org/10.1002/2016JA023825

Randall, C. E., Harvey, V. L., Singleton, C. S., Bailey, S. M., Bernath, P. F., Codrescu, M., Nakajima, H., and Russell III, J. M. (2007). Energetic particle precipitation effects on the Southern Hemisphere stratosphere in 1992-2005. J. Geophys. Res., 112(D8), D08308. https://doi.org/10.1029/2006JD007696

Rezac, L., Jian, Y., Yue, J., Russell III, J. M., Kutepov, A., Garcia, R., Walker, K., and Bernath, P. (2015). Validation of the global distribution of $\mathrm{CO}_{2}$ volume mixing ratio in the mesosphere and lower thermosphere from SABER. J. Geophys. Res., 120(23), 12067-12081. https://doi.org/10.1002/2015JD023955

Richmond, A. D. (1995). lonospheric electrodynamics using magnetic apex coordinates. J. Geomag. Geoelectr., 47(2), 191-212. https://doi.org/10.5636/jgg.47.191

Roble, R. G., and Ridley, E. C. (1987). An auroral model for the NCAR thermospheric general circulation model (TGCM). Ann. Geophys. A, 5(6), 369-382.

Roble, R. and Dickinson, R. (1989). How will changes in carbon dioxide and methane modify the mean structure of the mesosphere and thermosphere?. Geophysical Research Letters, 16, 1441-1444. https://doi.org/10.1029/GL016i012p01441 https://doi.org/10.5636/jgg.47.191

Seppälä, A., Lu, H., Clilverd, M. A., and Rodger, C. J. (2013). Geomagnetic activity signatures in wintertime stratosphere wind, temperature, and wave response. J. Geophys. Res. Atmos., 118, 2169-2183. https://doi.org/10.1002/jgrd.50236

Smith, A. K., Garcia, R. R., Marsh, D. R., and Richter, J. H. (2011). WACCM simulations of the mean circulation and trace species transport in the winter mesosphere. J. Geophys. Res., 116(D20), D20115. https://doi.org/10.1029/2011JD016083

Solomon, S. C., Qian, L. Y., and Roble, R. G. (2015). New 3-D simulations of climate change in the thermosphere. J. Geophys. Res., 120(3), 2183-2193. https://doi.org/10.1002/2014ja020886

Solomon, S. C., Liu, H. L., Marsh, D. R., Mclnerney, J. M., Qian, L. Y., and Vitt, F. M. (2018). Whole atmosphere simulation of anthropogenic climate change. Geophys. Res. Lett., 45(3), 1567-1576. https://doi.org/10.1002/2017GL076950

Svensmark, H., Enghoff, M. B., Shaviv, N. J., and Svensmark, J. (2017). Increased ionization supports growth of aerosols into cloud condensation nuclei. $\mathrm{Nat}$. Commun., 8(1), 2199. https://doi.org/10.1038/s41467-017-02082-2

Thébault, E., Finlay, C. C., Beggan, C. D., Alken, P., Aubert, J., Barrois, O., Bertrand, F., Bondar, T., Boness, A., ... Zvereva, T. (2015). International geomagnetic reference field: the 12th generation. Earth Planets Space, 67(1), 79. https://doi.org/10.1186/s40623-015-0228-9

Valet, J. P., and Meynadier, L. (1993). Geomagnetic field intensity and reversals during the past four million years. Nature, 366(6452), 234-238. https://doi.org/10.1038/366234a0

Wollin, G., Ericson, D. B., Ryan, W. B. F., and Foster, J. H. (1971). Magnetism of the earth and climatic changes. Earth Planet. Sci. Lett., 12(2), 175-183. https://doi.org/10.1016/0012-821X(71)90075-6

Yue, X. N., Hu, L. H., Wei, Y., Wan, W. X., and Ning, B. Q. (2018). lonospheric trend over Wuhan during 1947-2017: comparison between simulation and observation. J. Geophys. Res., 123(2), 1396-1409. https://doi.org/10.1002/2017JA024675

Zossi, B. S., Elias, A. G., and Fagre, M. (2018). lonospheric conductance spatial distribution during geomagnetic field reversals. J. Geophys. Res., 123(3), 2379-2397. https://doi.org/10.1002/2017JA024925 

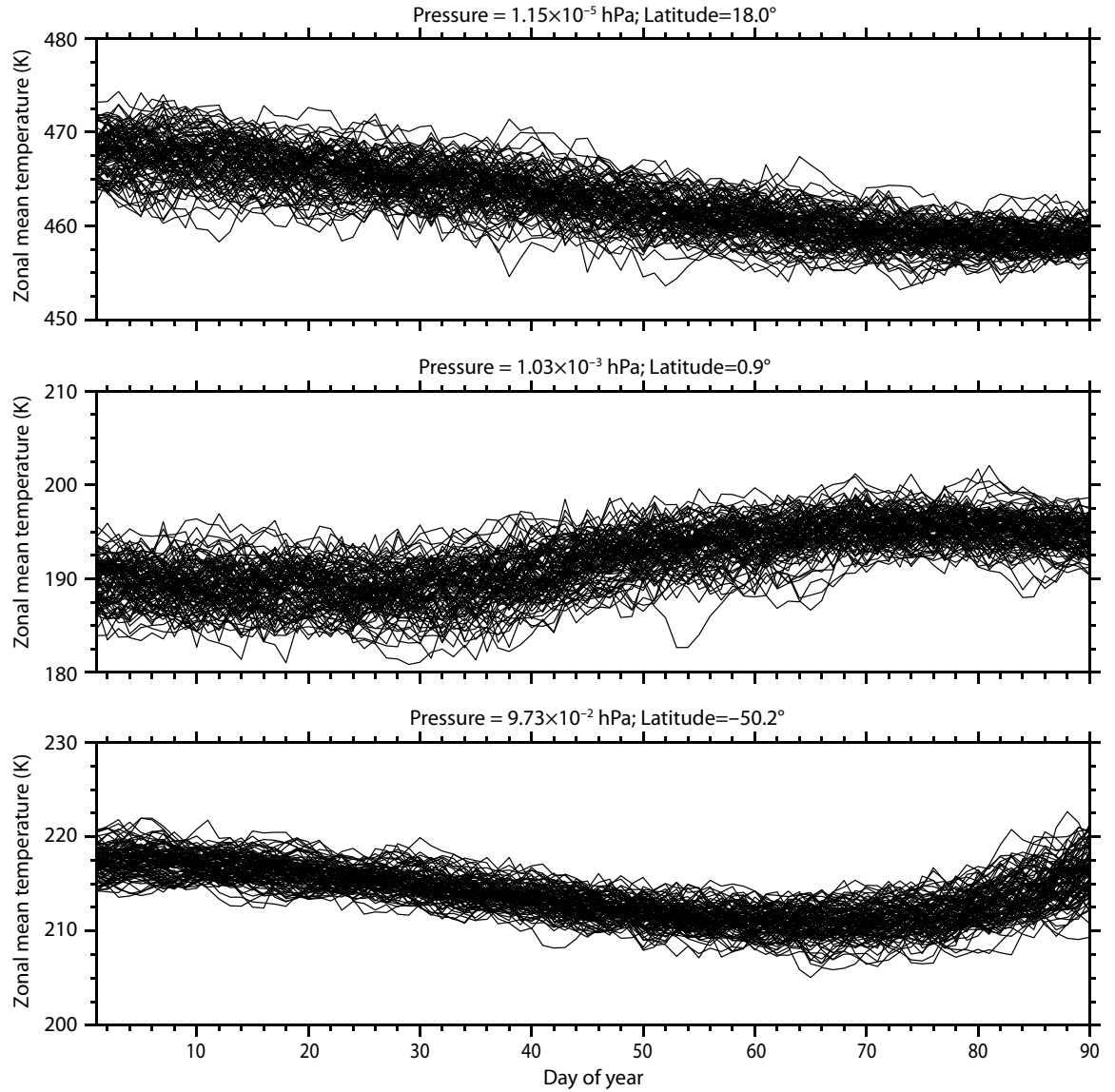

Figure S1. Day-to-day variations of zonal mean temperature for the ensemble of original-B case at different pressure levels and latitudes.
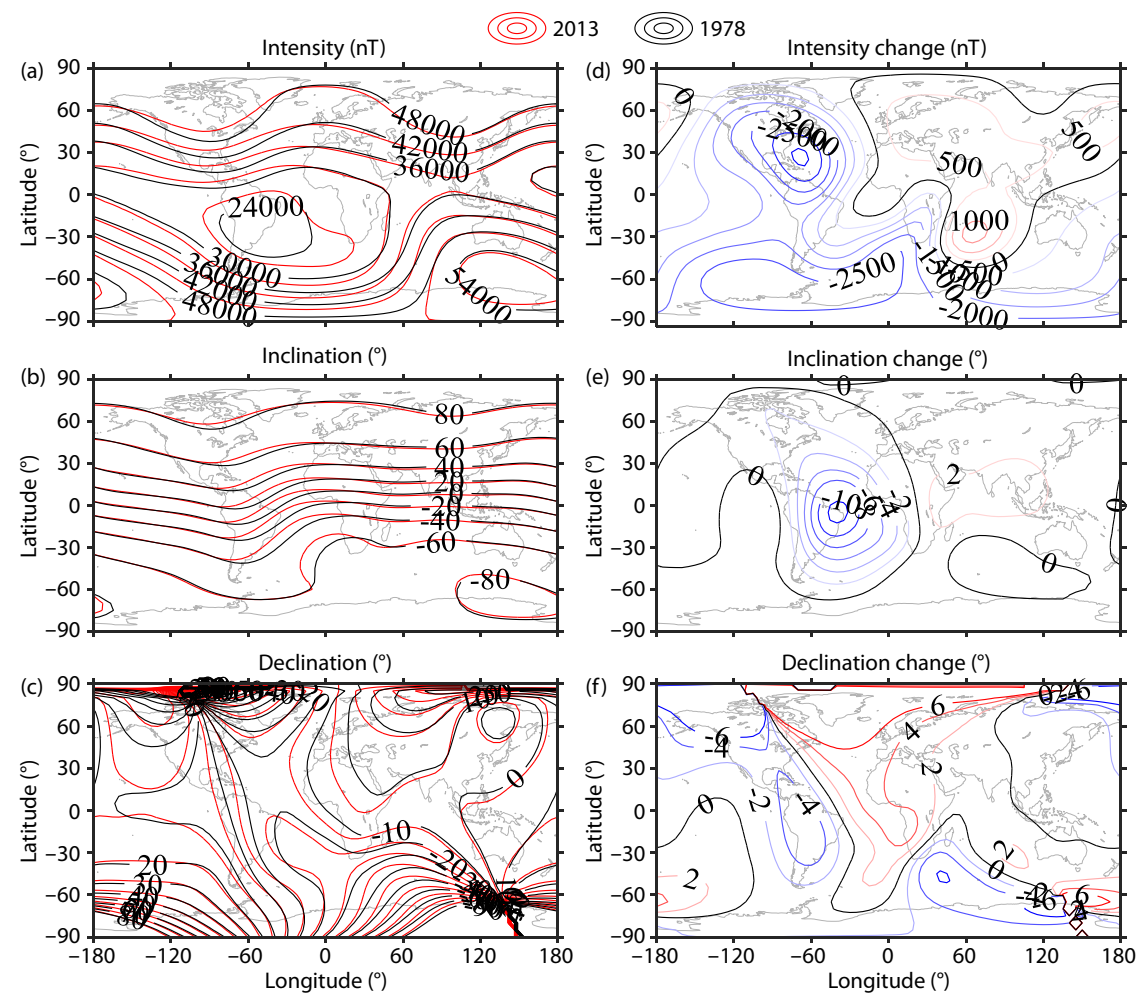

Figure S2. The (a) intensity, (b) inclination angle, and (c) declination angle of geomagnetic fields for 1978 (black) and 2013 (red). (d)-(f) show the corresponding differences. The grey lines are continental coastlines. 


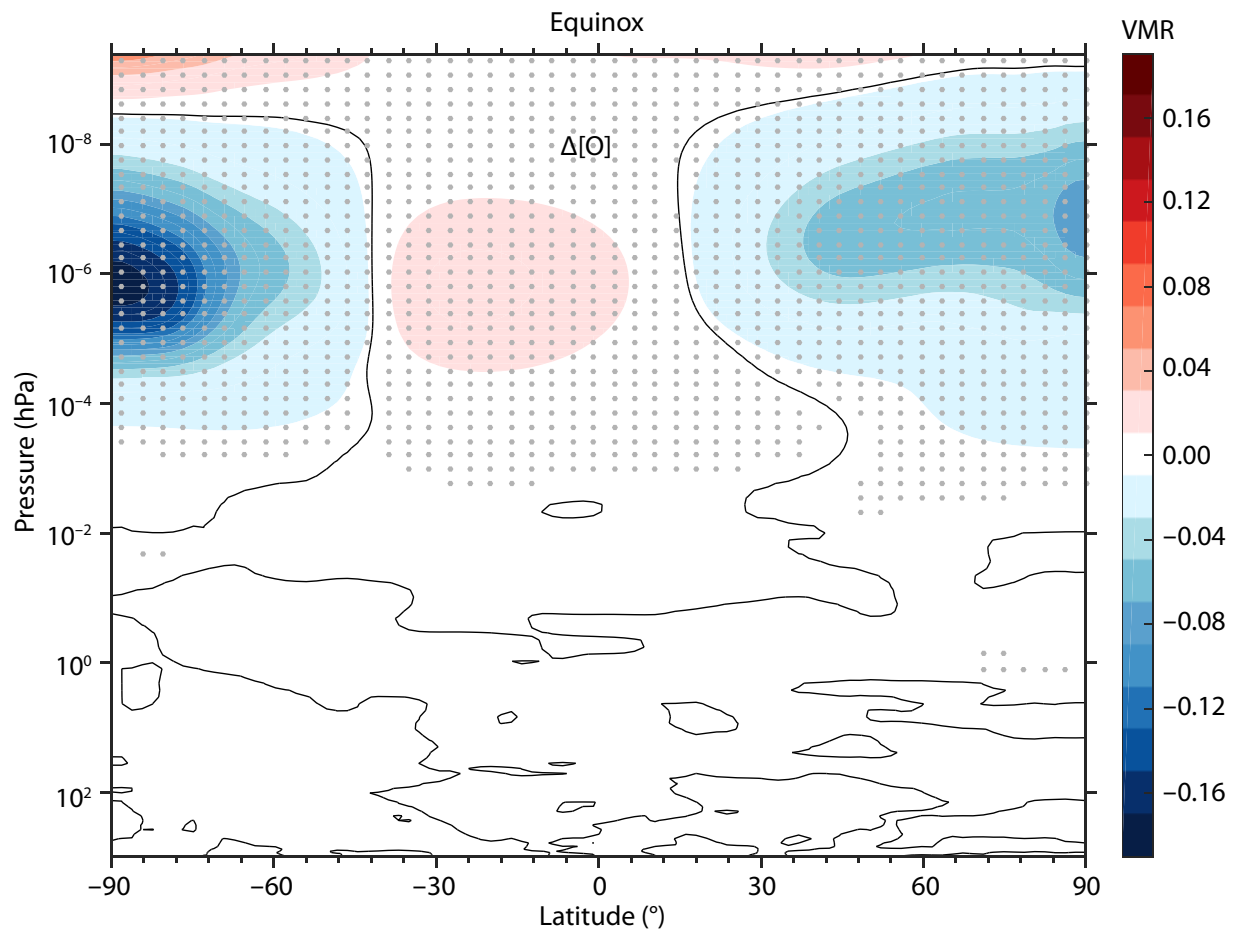

Figure S3. Differences of the zonal mean volume mixing ratio of atom oxygen in equinox. The grey dots indicate the area where the differences are statistically significant at the $99 \%$ significance level. The black lines indicate where the difference is zero.
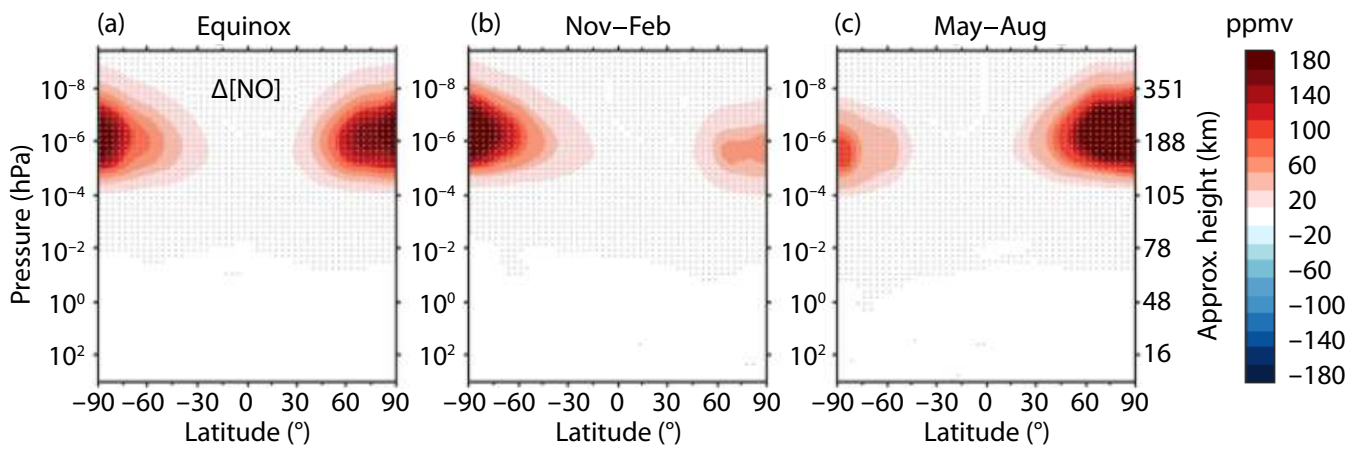

(d)
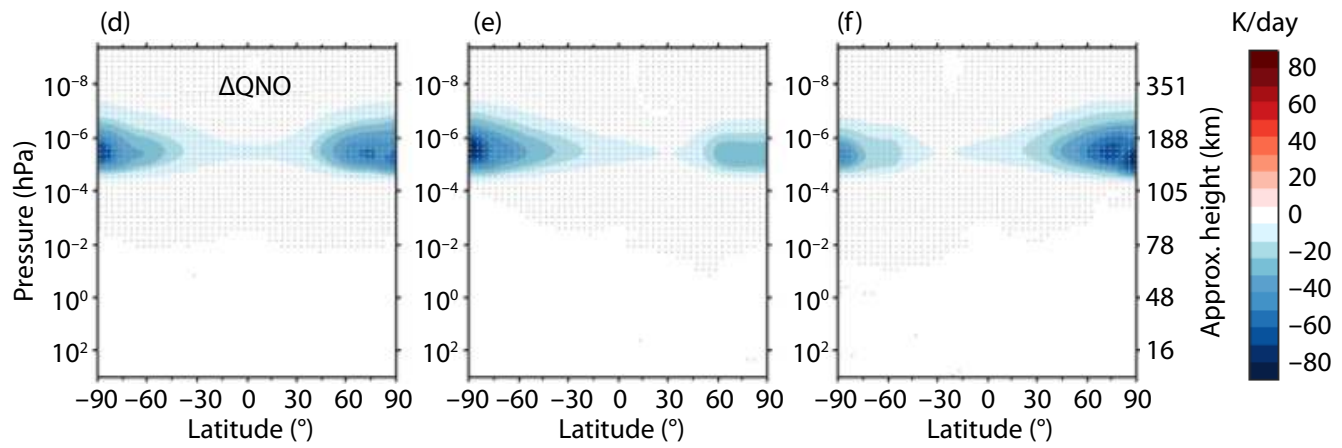

Figure S4. Differences of the zonal mean (top row) mixing ratio and (bottom row) heating rate of NO in (left) equinox, (middle) northern winter, and (right) northern summer. The grey dots indicate the area where the differences are statistically significant at the $99 \%$ significance level. The approximate height of corresponding pressure level is labelled on the right. 